\title{
Introduction to Gender and Media Revisited
}

\section{Tobias Raun, Maja Rudloff, Anne Mette Thorhauge, and Kjetil Sandvik}

MedieKultur 2016, 61, 1-5

Published by SMID | Society of Media researchers In Denmark | www.smid.dk The online version of this text can be found open access at www.mediekultur.dk

Gender is not a new concept in media studies. However, its uses and connotations have changed over time to include different types of problems such as the position of women in media industries, gendered stereotypes in mass media or, more recently, the fluidity and performance of gender inspired by queer studies. When, back in 1986, MedieKultur ran a special issue on "Women and Electronic Mass Media", the focus was specifically on women in media studies and the media industries. The shift of focus from "women" to this special issue's focus on "gender" is significant, and it echoes a change in many research programmes from women's studies to gender studies. This shift expands and multiplies the question of gender beyond "women" (and "men"), emphasizing gender as constructed and performative and as a plurality that does not necessarily fit heteronormative ideals. However, raising the issue of gender is still considered by many to be "a women's issue"; hence, gender is still often associated with and "sticks" to women, or it is perceived as a matter of addressing the power imbalances between "men" and "women". With this issue, we wish to highlight gender as a complex category that goes beyond a natural, given (binary) fact.

A revisitation of gender seems particularly relevant in the context of a contemporary and increasingly media-saturated, media-convergent, and globalized world. Decades of media research have shown that media is, arguably, a pervasive and powerful influence on our perceptions, experiences and conceptualizations of gender(ed) identities and their relations. However, while the influence of mass media's gender representations has long been the subject of feminist and queer theoretical interrogation, the past two decades 
have witnessed significant transformations of the subject being studied: the mediascape itself. The evolution of communication technologies and the advent and omnipresence of new digital media - including social and participatory media platforms and their inherent potential for interacting, connecting, protesting, and forming new relationships - have actualized and outlined new areas and topics of academic investigation. Assuming that a transformed mediascape has informed new notions of gender, it seems pertinent to ask, then, what (new) gender roles, representation patterns, receptions, readerships, identities, performances, and negotiations have emerged? This issue of MedieKultur explores some of the various ways in which gender and media intersect in today's mediascape - for example, how media in their different forms are influenced by and exert influence over political, social and cultural aspects of gender constructions and representations.

Thus, by naming the issue Revisiting Gender and Media, we wish to attend to new or alternative gender and media practices and reading strategies. In this themed issue, revisiting takes many forms - from demonstrating how cutting-edge theoretical perspectives from gender and cultural studies (such as queer, trans, disability and affect studies) can be analytically fruitful for media studies to investigations of new communication patterns, new media genres and formats. The articles offer conclusions emphasizing an overwhelming re-inscription and re-idealization of normative notions of gender within the current mediascape while also pointing to subversive gaps and possibilities.

This special issue brings together media studies, gender studies and cultural studies in order to explore the various ways in which gender and media intersect. The attempt to bridge these different fields of study has resulted in a colourful palette of contributions, marked by significant diversity in relation to methodology, theoretical departures and strategies of analysis. In the articles, gender resurfaces both as a field of study (gendered performances, identifications and representations) and as an analytical lens through which certain structures become apparent.

Employing gender as a lens through which to examine the popular culture of young children, this issue's first article by Fredrik Lindstrand, Eva Insulander and Staffan Selander provides a good example of how new media formats have expanded and altered our everyday confrontation with and experience of gender across modalities and genres. Focusing on the television series and a story-app for smartphones and tablets related to the children's brand Mike the Knight, Lindstrand, Insulander, and Selander show how new cross-media representations propose a rather limited and stereotypical image of gender. However, through the empirical example of pre-school girl "Alice" they also highlight the attempt of an individual to bypass these limited possibilities for gendered identification.

In a similar vein, gender is pointed out as an unstable signifier and a disrupted becoming by Cael Keegan, whose article "Revisitation: A trans phenomenology of the media image" is a queer/trans-phenomenological auto-reception of the meaning of cultural images. Keegan points to the re-negotiations in which transgender individuals engage; challenging and transforming whom certain normative, gendered, cultural images are supposed to attract 
and become attachable to. Here, media reception is illustrated as an affectively-invested act in which neither media producers nor media researchers can assume a smooth and 'rational' transmission of intended messages.

The implied gender positioning of media texts and the challenging of such positioning are also the topic of Anja Hirdman's article, "Speaking through the flesh: Affective encounters, gazes and desire as text in Harlequin romances". Exploring female readership, Hirdman re-evaluates and re-reads the denigrated Harlequin romances and shows that they are not just a repetitive girl-meets-boy book formula that maintains and eroticizes the unequal balance of power between the sexes, as feminist critics have argued. Hirdman calls our attention to the way in which the Harlequins focus on corporeal sensations and gazes in an extended literary transvestism, a double narrator perspective, which then offers readers an affective imaginary space in which the significance of the gendered body is re-made, reversed, and the male body is stripped of its unique position.

Maria Bee Christensen-Strynø's case study analysis of two disability-awareness-raising campaigns, "Mainstreaming and misfitting: Exploring disability and its intersection with gender in online disability awareness-raising videos", shows how gender is inseparable from other social categorizations such as disability. Christensen-Strynø offers an introduction to disability studies as a valuable prism through which to investigate gendered (new) media representations. Through an analysis of the two case studies, she points out, on one hand, how disability is mainstreamed or stabilized as a valid category of identity through the instalment of traditional visual codes of femininity while, on the other hand, it is re-evaluated as a misfit position through a commercialized hyper-aestheticization, which destabilizes the signifiers of both disability and gender.

In "Online kinship: Social media as a site for challenging and maintaining notions of gender and family", Rikke Andreassen analyses the communication patterns, articulations, stances and negotiations of the term "family" among the female members of a secret Facebook donor-family group. Andreassen demonstrates how the affordances of social media enable new kinship connections and affective ties to exist between half-siblings and their parents while the narratives being performed in the online donor group contribute to maintaining normative gender roles and upholding traditional ideals about the nuclear family, albeit in dispersed form. In this way, notions of kinship and family are both deconstructed and reconstructed online.

The final article in this volume, "If you don't act, you are not going to get anything': Professional identity and gender equality in Greek and Cypriot media organizations", Dimitra Dimitrakopoulou and Angeliki Gazi look at gender from an organisational macro-level, exploring gendered power distribution within media organisations. Drawing on a large survey exploring gender (in)equality in decision-making in media organisations, Gazi and Dimitrakopoulou show the persistence of organisational cultures and structures that constrain the promotion of women in decision-making positions. 
In Gender and Media Revisited, the question of gender goes beyond "women's issues" as well as the man-woman dichotomy. An undercurrent in many of the articles is the writing of Judith Butler, who has been very influential within gender studies in the last two decades by problematizing gender as a stable signifier. Gender is, as Butler famously puts it, a performative iteration, performed by various institutions and agents within a heterosexual matrix that requires and produces stable and coherent gendered beings (both in connection to sex/gender and over a lifetime) and establishes heterosexuality as the natural sexual desire and practice, thus constituting everything else as otherness and abnormality (Butler, 1999, pp. 23-24). The analysis by Keegan, Hirdman and Christensen-Strynø unpacks gender as a continuum, intersecting with and inseparable from other social categories and moving beyond and across a notion of gender as a binary material fact. Lindstrand, Insulander, Selander and Andreassen show how heteronormative notions of gender and family are re-inscribed and re-idealized, albeit in new and dispersed ways, while also pinpointing subversive gaps and possibilities. The last article by Dimitrakopoulou and Gazi returns to a more classic feminist approach, analysing how women are subordinate and disenfranchised in positions of power.

With Gender and Media Revisited, we wish to encourage more media researchers to include gender as a multiple and complex category in future studies.

This issue's "Open Section" includes one article. In "Critical reflections on the theory versus practice debate in communication for development", Linje Manyozo argues that, in order for universities and other educational bodies to provide an effective study programme for experts in communication for development, they need to focus more closely on innovative thinking within actual practices 'on the ground'. Furthermore, they need to ensure strong linkages with development studies departments to ensure that students are well-grounded in development theory and practice.

In our Classics series we are proud to provide our Danish/Scandinavian readers with yet another translation of a classic article. This time, Carsten Juul has translated Jean Baudrillard's "La précession des simulacres" (1978), which later became the opening article in his influential anthology Simulacra et simulation (1981). Timme Bisgaard Munk has written an excellent and extensive introduction to the article and to the work of Baudrillard as a whole.

In this issue, we introduce a new section to MedieKultur: "Debate". In this section, we bring articles of a polemic nature, addressing hot topics and, potentially, stirring up debate. The articles have not been filtered through our peer-review system because what characterizes articles in the Debate Section is that they may be personal, biased and provocative. The first article in this section is by Pelle Snickars, "Debunking public service? Meta-academic and personal reflections from inside the Swedish public service broadcasting commission", which provides a personal reflection on the author's work as a member of the Swedish public service broadcasting commission. The article takes the form of a meta-academic 
and personal reflection from inside the commission, where the author uses himself as a case study of the ways in which Swedish media research on public service tend to be biased (in favour of public service).

Tobias Raun, PhD

Assistant professor

Department of Communication and Arts

Roskilde University, Denmark tobiasra@ruc.dk

Maja Rudloff, PhD

Assistant professor

Department of Communication and Arts

Roskilde University, Denmark mrudloff@ruc.dk

Anne Mette Thorhauge, PhD Associate professor Department of Media, Cognition and Communication University of Copenhagen, Denmark annemette@thorhauge.dk

Kjetil Sandvik, PhD

Associate professor

Department of Media, Cognition and Communication University of Copenhagen Denmark Sandvik@hum.ku.dk 